\title{
Advancement in Microstructural, Optical, and Mechanical Properties of PVA (Mowiol 10-98) Doped by ZnO Nanoparticles
}

\author{
N. B. Rithin Kumar, ${ }^{1}$ Vincent Crasta, ${ }^{2}$ and B. M. Praveen ${ }^{3}$ \\ ${ }^{1}$ Department of Physics, Srinivas School of Engineering, Mukka, Mangalore, Karnataka 574146, India \\ ${ }^{2}$ Department of Physics, St. Joseph Engineering College, Vamanjoor, Mangalore, Karnataka 575028, India \\ ${ }^{3}$ Department of Chemistry, Srinivas School of Engineering, Mukka, Mangalore, Karnataka 574146, India
}

Correspondence should be addressed to Vincent Crasta; vcrasta@yahoo.com

Received 31 May 2014; Accepted 27 October 2014; Published 20 November 2014

Academic Editor: Ali Hussain Reshak

Copyright (C) 2014 N. B. Rithin Kumar et al. This is an open access article distributed under the Creative Commons Attribution License, which permits unrestricted use, distribution, and reproduction in any medium, provided the original work is properly cited.

\begin{abstract}
The current paper explores the preparation of PVA nanocomposites by doping with zinc oxide ( $\mathrm{ZnO}$ ) nanoparticles using the method of coagulation and solvent casting technique. The dopant zinc oxide nanoparticle is prepared by simple precipitation method and is confirmed by the X-ray diffraction (XRD) studies. The XRD studies explore that the average particle size of the synthesized nanoparticles is $55 \mathrm{~nm}$ and show that the crystallinity factor of PVA nanocomposites is influenced by the interaction occurring between the PVA main chain and the $\mathrm{ZnO}$ nanoparticle. The FTIR spectroscopy suggests that the formulation of complexes occurring between the dopants and the PVA main chain is due to inter or intra molecular hydrogen bonding. UV-vis spectra explore the dramatic decrease in the optical energy gap of nanoparticles doped polymer composites and the variations of Urbach energy $\left(E_{\mathrm{u}}\right)$ related to crystallinity for various dopant concentrations. The mechanical properties of the PVA nanocomposites were explored using universal testing machine (UTM) that reflects that, for $x=15 \%$ doping concentration, there is an increase in the tensile strength, stiffness, and Young's modulus, whereas, for $x=7.5 \%$ concentration, the percentage total elongation at fracture is found to be the maximum. The morphological behavior and homogenous nanoparticle distribution in the composites were examined by scanning electron microscopy (SEM) and energy-dispersive X-ray spectroscopy (EDAX).
\end{abstract}

\section{Introduction}

In the present generation, nanoparticles of transition metal oxides (TMOs) are the main areas of materials research due to their wide applications in many areas. In spite of these TMOs, zinc oxide nanoparticles are used in numerous applications like UV absorption, antibacterial treatment, and so forth [1-4]. Nowadays, doping of $\mathrm{ZnO}$ nanoparticles into a basic polymer matrix shows a very significant role for improving the physical parameters of the composite materials having very unique potential applications in various fields [5-7]. These nanoparticles generally tend to form a complex with the polymer chain and thereby increase the physical parameters of the polymer composites. In recent years, polyvinyl alcohol (PVA) is used as a basic polymer because of its unique properties such as good chemical stability, biodegradable, eco-friendly, electrical, and optical properties, and hydrophilicity $[8,9]$. The significant feature of PVA is its semicrystalline nature that is the presence of both crystalline and amorphous regions causing crystal-amorphous interfacial effects which increases the physical properties. These crystal-amorphous regions are well separated by an intermediate degree of ordering causing the PVA macromolecule to produce numerous crystalline and amorphous phases.

In this current paper, initially, zinc oxide ( $\mathrm{ZnO}$ ) nanoparticles are prepared by precipitation method and then doped into the PVA matrix by coagulation technique to prepare the polymer nanocomposites by utilizing simple solvent casting method. The crystalline and morphological properties were investigated using X-ray diffraction (XRD), FTIR, scanning electron microscopy (SEM), and energy-dispersive X-ray spectroscopy (EDAX). The information regarding the optical 
properties and Urbach energies of the films is studied using UV/visible spectroscopy. The mechanical properties were investigated using universal testing machine (UTM).

\section{Experimental Techniques}

2.1. Preparation of $\mathrm{ZnO}$ Nanoparticles. The nanoparticles of $\mathrm{ZnO}$ were synthesized according to Nejati et al. [10]. The $\mathrm{NaOH}$ and $\mathrm{Zn}\left(\mathrm{NO}_{3}\right)_{2} \cdot 6 \mathrm{H}_{2} \mathrm{O}$ chemicals were procured from Sigma Aldrich, Germany. The required solution of $\mathrm{NaOH}$ is prepared by dissolving $40 \mathrm{gm}$ of $\mathrm{NaOH}$ in one liter of deionizing water and is heated up to $80^{\circ} \mathrm{C}$ with continuous stirring kept at $1000 \mathrm{rpm}$ in temperature controlled magnetic stirrer, kept for 1 hour. For this prepared solution, a $250 \mathrm{~mL}$ solution of $0.5 \mathrm{M} \mathrm{Zn}\left(\mathrm{NO}_{3}\right)_{2} \cdot 6 \mathrm{H}_{2} \mathrm{O}$ was added and the reaction mixture was further kept at constant stirring rate of $1000 \mathrm{rpm}$ for two hours keeping the temperature at $80^{\circ} \mathrm{C}$. The precipitated solution formed from the above reaction was separated using a centrifuge to obtain $\mathrm{ZnO}$ and the obtained residue is washed several times with deionized water until all the traces of $\mathrm{NaOH}$ are removed. The obtained $\mathrm{ZnO}$ nanopowders were then dried at $90^{\circ} \mathrm{C}$ and kept in oven for about 8 hours and the yield was about $92 \%$. The crystalline structure and morphology of $\mathrm{ZnO}$ nanopowder were evaluated by XRD and SEM.

2.2. Preparation of Pure and Doped PVA Nanocomposites. PVA (Mowiol 10-98) compound of fully hydrolysed grade was procured commercially from Sigma Aldrich, Germany, and used as basic polymeric matrix. The PVA used as a basic polymer compound has molecular weight $M_{W}=61000 \mathrm{~g} / \mathrm{mol}$ with degree of polymerization $P_{W}=1400$, having bulk density of $0.4-0.6 \mathrm{~g} \mathrm{~cm}^{-3}$. A polymer nanocomposite films are prepared by mixing a mass $W_{d}$ of the dopant (nanoparticles) in a mass $W_{p}$ of the polymer. Thus, the percentage weight fraction $(x \%)$ of the dopants is evaluated by the following equation:

$$
x \%=\frac{W_{d}}{\left(W_{d}+W_{p}\right)} \times 100 .
$$

About “ $x$ ” weight percentage zinc oxide nanoparticles $(\mathrm{ZnO})$, where $x=0 \%, 1 \%, 5 \%, 7.5 \%, 10 \%, 14 \%$, and $15 \%$ weight, were taken and dispersed separately each in $5 \mathrm{~mL}$ of distilled water taken in beaker and sonicated by probe ultrasonicator for 10 minutes. A $6 \mathrm{~g}$ of solid PVA is made to dissolve in $100 \mathrm{~mL}$ of distilled water, kept at constant stirring rate of $1000 \mathrm{rpm}$ for one hour simultaneously, heating the mixture at $90^{\circ} \mathrm{C}$ until the polymer dissolves completely to form a clear viscous solution. The PVA solution achieved was divided into six equal parts and each part of viscous solution of prepared PVA was treated by adding " $x$ ” weight percentage of $\mathrm{ZnO}$ nanoparticles, where $x=0 \%, 1 \%, 5 \%, 7.5 \%, 10 \%$, $14 \%$, and $15 \%$ weight concentrations dispersed in distilled water and ultrasonically sonicated by probe ultrasonicator for 20 minutes to make homogenous distribution of $\mathrm{ZnO}$ nanoparticles in PVA matrix. The polymer viscous solution was then allowed to cast into a polymer composite film using a clean Petri dish and the solvent is dried in air for three days at room temperature. Later, the composite films were peeled off from the Petri glass plate and placed in vacuum desiccators for further characterization. The thickness of the obtained polymer nanocomposite films was investigated using dial thickness gauge (Mitutoyo, Japan) by taking three trials at different places and mean thickness of the film was found in the range between 100 and $150 \mu \mathrm{m}$.

2.3. Physical Measurements. The X-ray diffraction spectra of the different polymer composite were investigated to study regarding crystalline parameters samples by using a Bruker D8 Advance X-ray diffractometer having Ni filter and $\mathrm{Cu} \mathrm{K} \alpha$ radiation of wavelength $\lambda=1.5406 \AA$ using a graphite monochromator. The scanning was performed with scanning speed $2^{\circ} / \mathrm{min}$ in the $2 \theta$ range $10-80^{\circ}$. Fourier transformation infrared spectroscopy (FTIR) studies of the pure and doped PVA composite films were examined using JASCO FTIR 4100 type A spectrophotometer in the wave number range 400$4000 \mathrm{~cm}^{-1}$ having a resolution of $4 \mathrm{~cm}^{-1}$. The information about the energy gap and other optical studies of the PVA nanocomposites was determined using JASCO V-630 UVvisible spectrophotometer taken in the wavelength range 190$1100 \mathrm{~nm}$. The investigation of mechanical parameters like tensile strength, percent elongation (\%), and modulus of elasticity was carried out using universal testing machine (LLOYD LRX Plus-5 KN, London, UK). The mechanical tests were performed according to ASTM D-882 standard test (ASTM, 1992) and the results were analyzed using NEXYGEN Plus software. Polymer composites of rectangular shape of dimension $25 \times 100 \mathrm{~mm}$ were used for the determination of all mechanical parameters. The nanoparticles distribution in the PVA matrix and surface morphological behavior were known using JEOL JSM-6380LA scanning electron microscopy (SEM) and energy-dispersive X-ray spectroscopy (EDAX).

\section{Results and Discussion}

3.1. XRD Studies of Pure ZnO, Pure PVA, and ZnO Doped PVA Samples. The XRD spectrum is taken in the $2 \theta$ range from 10 to $80^{\circ}$, showing the peaks related to $\mathrm{ZnO}$ nanoparticles. The numerous crystalline peaks observed at $2 \theta=32.33$, $35.15,36.93,48.49,57.66,64.23,67.67,69.35,70.46$, and 74.29 degrees resemble $\mathrm{ZnO}$ nanoparticles (ICSD Collection Code: 154490 and International Center for Diffraction Data, JCPDS 5-0664). Apart from this, no extra peaks of impurity were observed in the spectrum portentous and the high purity of $\mathrm{ZnO}$ was obtained during synthesizing as shown in Figure 1. The average particle size of prepared $\mathrm{ZnO}$ nanoparticles can be evaluated by the first approximation of Debye-Scherrer formula [11]:

$$
D=\frac{0.9 \lambda}{B \cos \theta}
$$

where $D$ is the average size of the particles, $\lambda$ is the wavelength of $\mathrm{X}$-ray radiation used, $B$ is the full width at half maximum intensity of the peaks, and $\theta$ is the diffraction angle.

The average particle size " $D$ " evaluated from DebyeScherrer formula for the prepared $\mathrm{ZnO}$ nanoparticles is $55 \mathrm{~nm}$. 


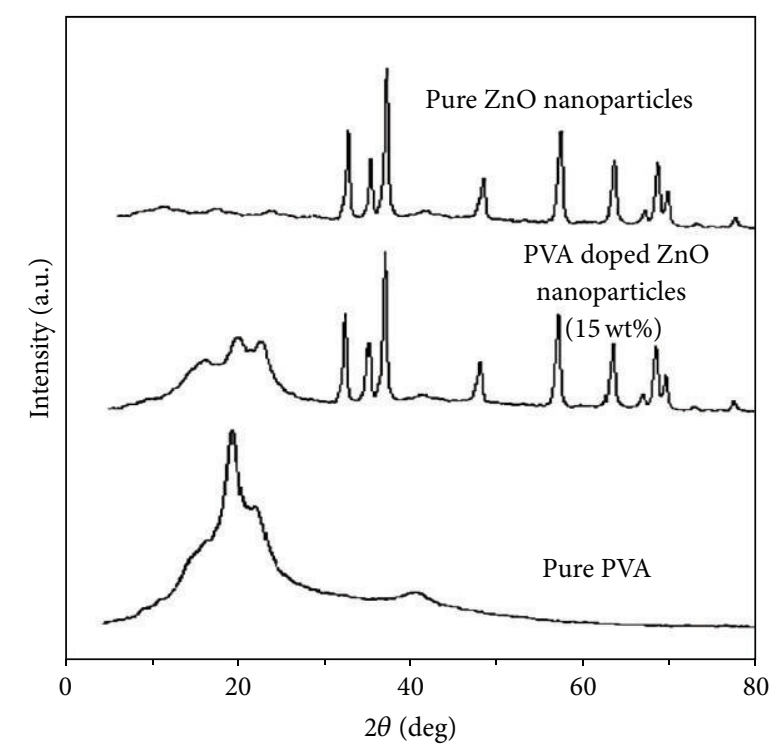

FIgure 1: X-ray diffraction peaks of Pure $\mathrm{ZnO}$ nanoparticles, PVA doped $\mathrm{ZnO}$ composites, and pure PVA films.

Further, the XRD spectrum explores the semicrystalline nature of the pure PVA as well as $\mathrm{ZnO}$ doped PVA nanocomposite films. In case of pure PVA, a broad intense peak observed at scattering angle $\left(19^{\circ}<2 \theta<20^{\circ}\right)$ represents the " $d$ " spacing value $4.57 \AA$ for pure PVA. The occurrence of semicrystalline nature of PVA is mainly because of the existence of strong intermolecular hydrogen bonding between PVA molecules. After doping, the widening of crystalline peaks obtained at the range $2 \theta=19^{\circ}<2 \theta<22^{\circ}$ implies that the particle size decreases. This decrease in the particle size is mainly because of the interaction occurring between main chain of PVA and $\mathrm{ZnO}$ nanodopants. The diffraction peaks are also confirmation of $\mathrm{ZnO}$ nanoparticles and the formation of composites.

The crystallinity is nothing but the weight fraction of the crystalline percentage of a polymer. The physical characteristics of any polymer are generally dependent on the crystalline parameters. The XRD spectrum determines the crystallinity factors of these composites:

$$
\text { Crystallinity } \%=\frac{(\text { total area of crystalline peaks })}{(\text { total area of all peaks })} \times 100 .
$$

The value of percentage crystallinity for $\mathrm{PVA} /(x) \mathrm{ZnO}$ for $x=0 \%$ is found to be $56.86 \%$, whereas, for $x=15 \%$, it is $65.36 \%$. This change in crystallinity signifies the structural regularity occurring in the main chains of the polymeric molecules on doping.

3.2. FTIR Analysis of $Z n O$ Doped PVA Nanocomposites. The FTIR spectral analyses of pure and $\mathrm{ZnO}$ nanoparticles doped PVA composites were explored and are presented in Figure 2. From the FTIR data, an intense broadband was observed at the wave number range $3624.55 \mathrm{~cm}^{-1}$, representing the $\mathrm{O}-\mathrm{H}$

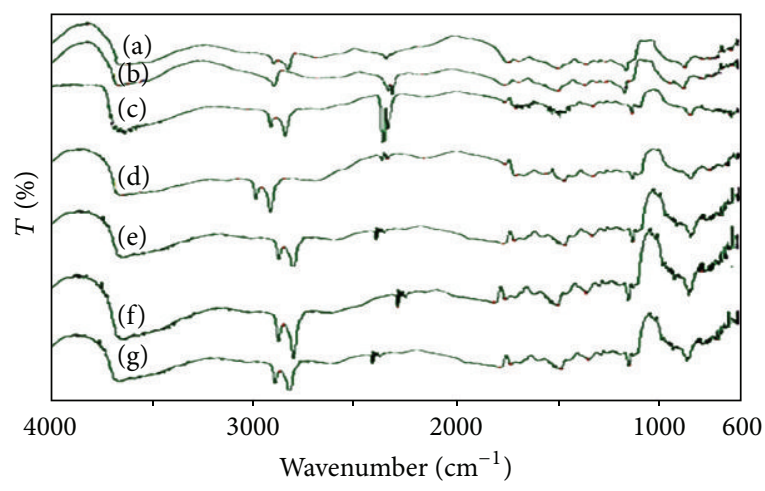

FIGURE 2: FTIR spectra of PVA/ $(x) \mathrm{ZnO}$ nanocomposites for (a) $x=$ $0 \mathrm{wt} \%$, (b) $x=1 \mathrm{wt} \%$, (c) $x=5 \mathrm{wt} \%$, (d) $x=7.5 \mathrm{wt} \%$, (e) $x=$ $10 \mathrm{wt} \%$, (f) $x=14 \mathrm{wt} \%$, and (g) $x=15 \mathrm{wt} \%$.

stretching vibration associated with PVA molecule $[12,13]$. It is observed that after the action of $\mathrm{ZnO}$ nanoparticles dispersing in the PVA matrix the FTIR spectra exhibit several irregular shifts related to corresponding bands with change in intensities of pure PVA as presented in Table 1. The irregular shifts indicated in the spectrum are mainly because of the orderly arranged hydroxyl groups of the polyvinyl alcohol chain accomplished by forming stable complex compounds or else bonding with certain substances. This intimates us regarding the extensive interaction of PVA and with $\mathrm{ZnO}$ nanoparticles. The observed variations may also link with defects generated by the charge transfer reaction existing between the PVA chain and the $\mathrm{ZnO}$ nanodopant. These justifications strengthen the interaction occurring between the doped $\mathrm{Zn}$ ions and PVA acetyl group (as presented in Schemes 1 and 2). The shifts in acetyl C-O stretching and also in $\mathrm{CH}_{2}$ of PVA molecules support the existence of chemical interaction occurring between $\mathrm{Zn}$ and PVA matrixes through intra-/intermolecular hydrogen bonding existing between them. The complex modification that occurred within the PVA molecules with $\mathrm{ZnO}$ can be understood as represented in Scheme 1. The dopant added also adjusts the wagging, bending, skeletal, and out of plane vibrations related to PVA. The vibrational peak observed in the wave number range $800-600 \mathrm{~cm}^{-1}$ signifies the $\mathrm{Zn}-\mathrm{O}$ indicating the formation of complex with the PVA matrix.

3.3. UV-Visible Spectroscopy Studies. The UV/visible spectrum for various concentrations of the composite samples was detected. The spectra of pure and $\mathrm{ZnO}$ nanoparticles dispersed PVA are presented as given in Figure 3. It is well known that pure PVA absorbs the radiation strongly in the wavelength region 200-400 $\mathrm{nm}[14,15]$. Figure 3 signifies the shift in both absorption bands and the band edges towards the higher wavelengths with different absorption intensities for different concentrations of doped PVA samples. These absorption band shifts give an idea of the formation of inter-/ intramolecular hydrogen bonding existing between $\mathrm{Zn}$ ions with the adjacent $\mathrm{OH}$ groups of the PVA main chain. The increase in absorption is mainly due to the increase in $\mathrm{ZnO}$ 
TABLE 1: Asymmetrical shifts observed in FTIR spectra of doped PVA nanocomposites.

\begin{tabular}{|c|c|c|c|c|c|}
\hline Sl. number & Sample & $\begin{array}{c}\mathrm{C}-\mathrm{O} \\
\text { stretching of acetyl group } \\
\mathrm{cm}^{-1}\end{array}$ & $\begin{array}{c}\mathrm{CH}_{2} \\
\text { vibrations } \\
\mathrm{cm}^{-1}\end{array}$ & $\begin{array}{c}\mathrm{C}-\mathrm{H} \\
\text { asymmetric stretching vibration } \\
\mathrm{cm}^{-1}\end{array}$ & $\begin{array}{c}\mathrm{C}-\mathrm{H} \\
\text { symmetric stretching vibration } \\
\mathrm{cm}^{-1}\end{array}$ \\
\hline 1 & Pure PVA & 1151.29 & 1479.13 & 2996.84 & 2878.24 \\
\hline 2 & $\mathrm{PVA} / 1 \% \mathrm{ZnO}$ & 1150.96 & 1479.14 & 2997.13 & 2881.13 \\
\hline 3 & $\mathrm{PVA} / 5 \% \mathrm{ZnO}$ & 1149.46 & 1479.15 & 2996.14 & 2879.72 \\
\hline 4 & $\mathrm{PVA} / 7.5 \% \mathrm{ZnO}$ & 1149.09 & 1478.68 & 2998.13 & 2879.12 \\
\hline 5 & $\mathrm{PVA} / 10 \% \mathrm{ZnO}$ & 1149.01 & 1473.12 & 2996.08 & 2878.2 \\
\hline 6 & $\mathrm{PVA} / 14 \% \mathrm{ZnO}$ & 1151.14 & 1480.13 & 2996.18 & 2877.8 \\
\hline 7 & $\mathrm{PVA} / 15 \% \mathrm{ZnO}$ & 1150.73 & 1480.05 & 2997.01 & 2877.6 \\
\hline
\end{tabular}

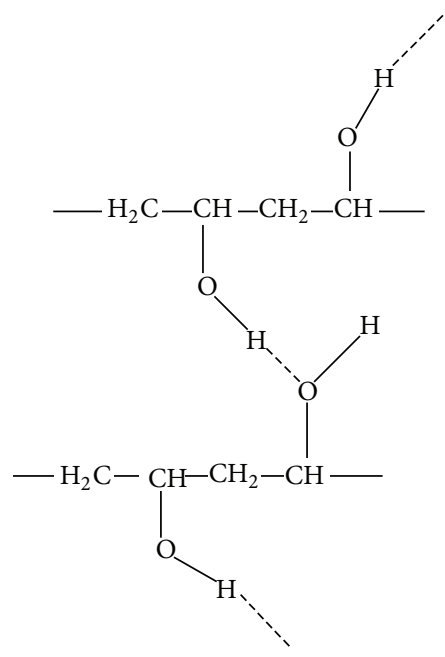

Intermolecular hydrogen bonding

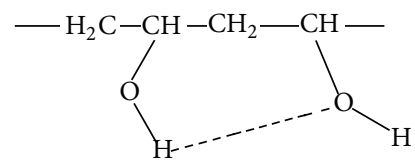

Intramolecular hydrogen bonding

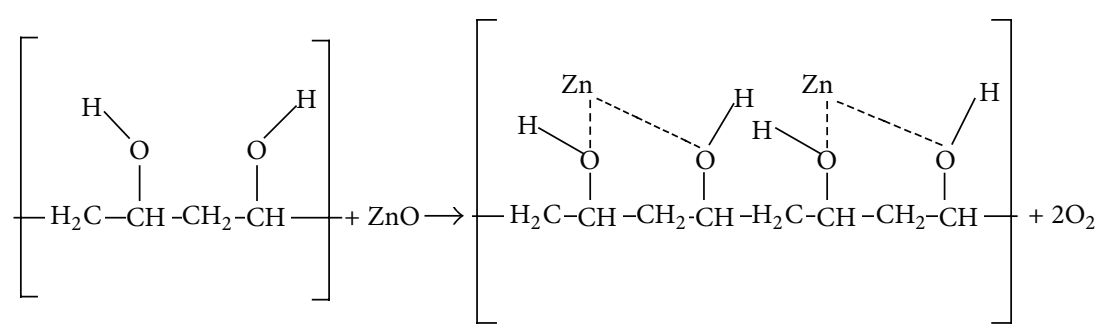

Scheme 1
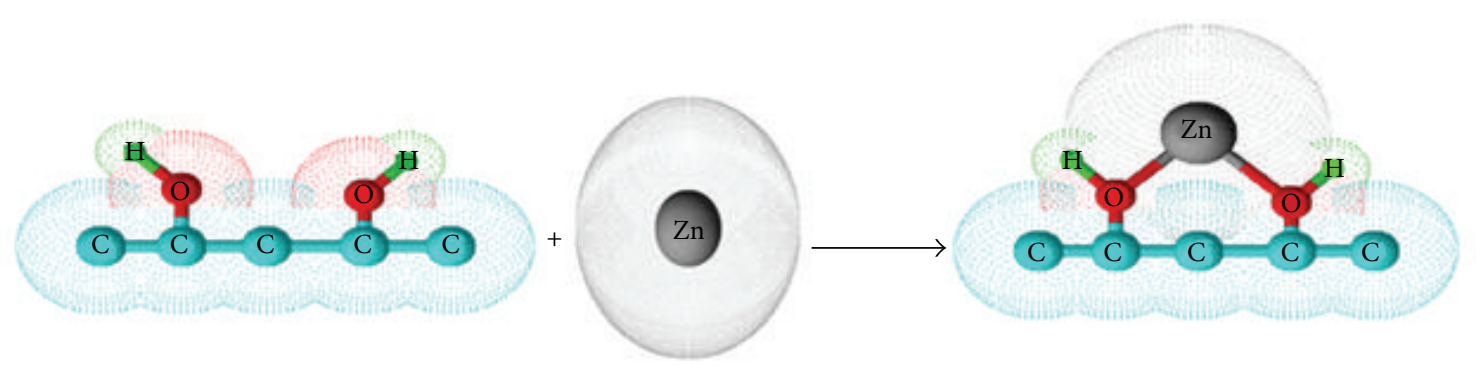

Scheme 2 


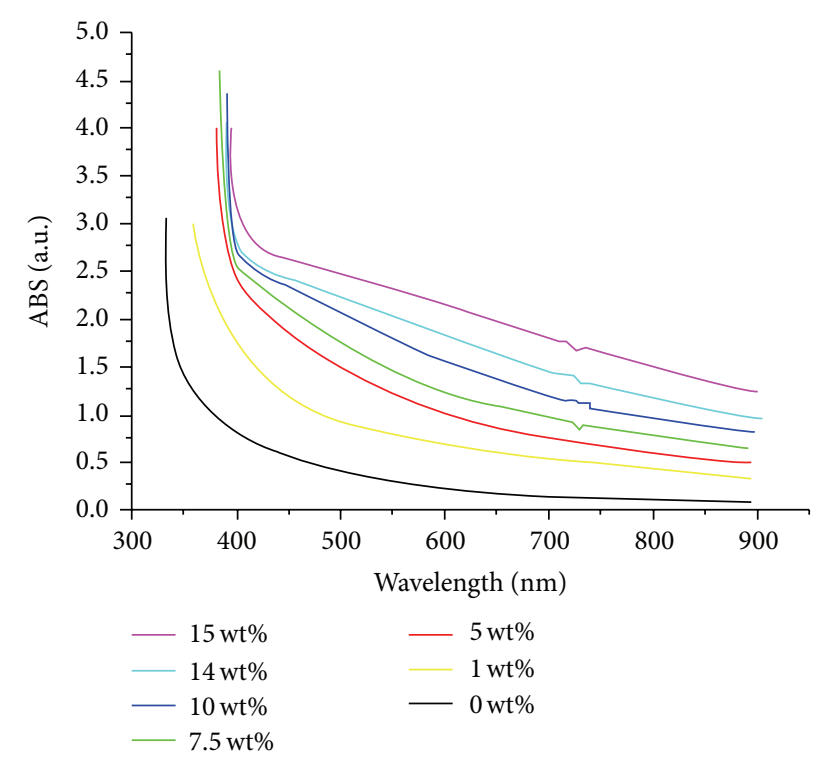

FIgURE 3: UV-visible spectra of pure and $\mathrm{ZnO}$ nanoparticles doped PVA composites.

concentration causing more and more inter-/intrahydrogen bonding. This can be enlightened more by using Beer's law which states that the absorption of radiation is directly proportional to the number of absorbing molecules in the sample. The shift witnessed in the absorption edge of the doped PVA composites is essentially due to the variation in crystalline parameters which in turn changes the energy band gap. Equation (4) represents the relation between the absorption coefficients $\alpha$ with photon energy

$$
\alpha=\frac{2.303 A}{d},
$$

where $A$ is absorbance and $d$ is the thickness of composite sample.

It is well known that classical Tauc's expression relates absorption coefficient $\alpha$ and the optical band gap $E_{g}$. From the UV-visible spectra, the optical energy band gap is determined by transforming the spectra into Tauc's plots using the frequency-dependent absorption coefficient as given by Mott and Devis $[16,17]$ :

$$
\alpha(\nu)=\frac{\beta\left(h \nu-E_{g}\right)^{r}}{h \nu},
$$

where $\beta$ is a constant and the exponent $r$ is an empirical index which is equal to 2 for indirect allowed transition in the quantum mechanical sense responsible for optical absorption.

The linear behavior of curve obtained by plotting of the product of absorption coefficient and photon energy $(\alpha h \nu)^{0.5}$ versus the photon energy $(h \nu)$ at room temperature signifies the indirect allowed transition. The linear portion of the curve is further extrapolated to a point $(\alpha h \nu)^{0.5}=0$, providing the optical energy band gap $E_{g}$ value for the pure as well as for the doped PVA films (Figure 4). Hence, indirect transition can be assumed between the valence and conduction bands.

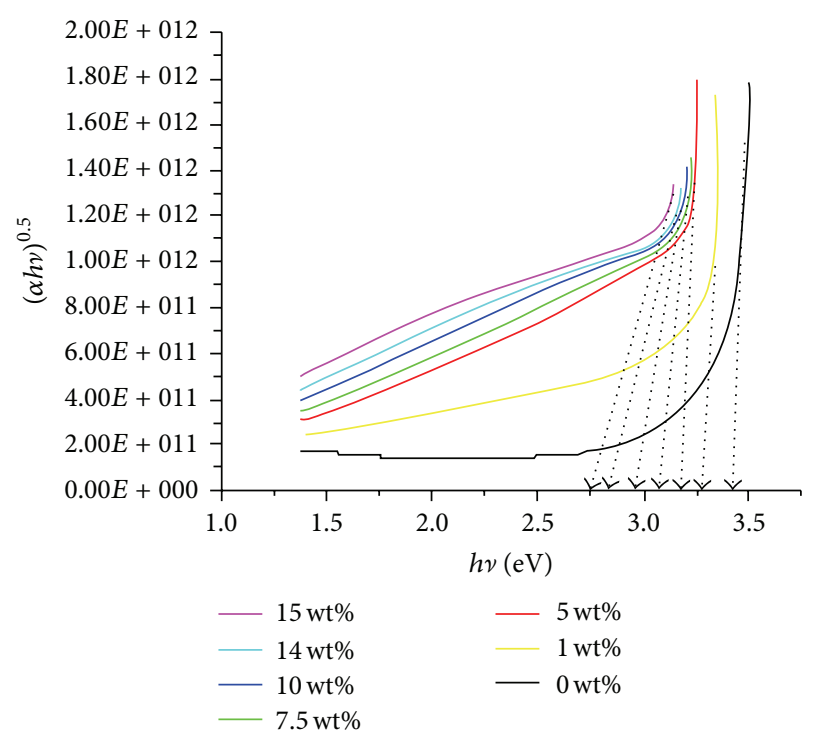

FIGURE 4: Optical energy band gap of pure and doped PVA nanocomposites for various doping concentrations.

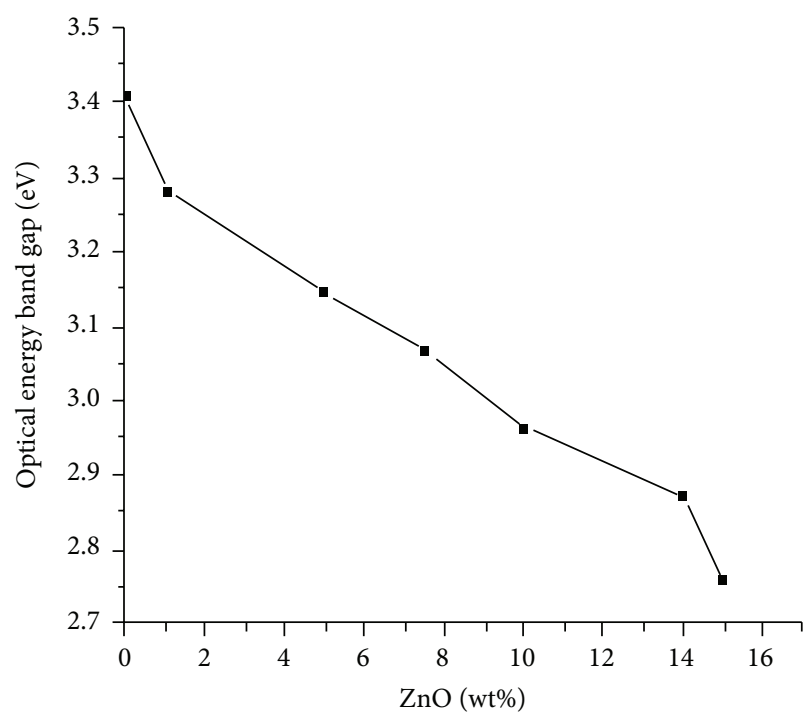

FIgURE 5: Variation of the optical energy band gap of the pure and ZnO doped PVA composites.

The values of $E_{g}$ calculated for various dopant concentrations of the composite samples are presented in Figure 5. It is very clear from Figure 5 that as the dopant concentration increases the band gap value decreases. The decrease in the optical energy gap $\left(E_{g}\right)$ values is due to the presence of local cross-linking that occurred within the noncrystalline phase of the composite polymer. This increase in the local cross-linking further increases the degree of ordering in PVA backbone and thereby decreases the energy gap values. Same observations are observed in XRD spectra, indicating the interaction of $\mathrm{ZnO}$ nanodopants with the main chain of PVA molecule and tending to form complex through intra- $/$ intermolecular hydrogen bonding. This complex formation 
causes the microstructural variation occurring between the nanoparticle and the basic polymer matrix. This change in microstructural leads to the decrease of the energy band gap $E_{g}$ of the polymer composites (Figure 5).

The crystalline or amorphous nature of prepared polymer composites is elucidated by using optical absorption data. In the composites, the absorption of radiations generally takes place if $h v \leq E_{g}$, signifying the presence of the tail states in the forbidden gap which is very close to the energy of the mobility edge. The Urbach energy $\left(E_{\mathrm{u}}\right)$ which determines the crystalline or amorphous nature of the composite is related to the absorption coefficient $\alpha(\nu)$ at higher wavelength in the spectrum or else at low absorption levels as follows [18]:

$$
\alpha(h v)=\alpha_{0} \exp \left(\frac{h \nu}{E_{\mathrm{u}}}\right),
$$

where $\alpha_{0}$ is a constant and $E_{\mathrm{u}}$ is called Urbach energy. It is well known that the value of $\alpha_{0}$ generally depends only on the optical energy gap value. The Urbach energy $E_{\mathrm{u}}$ interprets the disorder that occurred in the system that is generally understood by the thickness of the tail of localized states in the forbidden band gap. The Urbach rule for any sample signifies the exponential dependence of $\alpha(\nu)$ on energy of photon $(h \nu)$. The values presented in Table 2 are the Urbach energy $\left(E_{\mathrm{u}}\right)$ obtained by plotting the graph of exponential dependence of $\alpha(\nu)$ versus energy of photon $(h v)$ and the linear region of curve is fitted by least square fit technique. It is very clear from the table that as $\mathrm{ZnO}$ nanodopants concentration increases, the values of $E_{\mathrm{u}}$ increases. The mobility perception is responsible for the observed variations occurred in Urbach energies in case of doped polymer composites [17]. These nanodopants induce an additional defect states and formation of complex inside the polymer matrix. Generally, the nanoparticle doping concentration increases the density of localized states, creating more and more additional defects. Thus, the increase in the additional defects overlaps and extends the mobility gap. Hence, these defects overlap and complex formation enhances the Urbach energy when $\mathrm{ZnO}$ dopant increases in the polymer matrix. Hence, the value of Urbach energy $\left(E_{\mathrm{u}}\right)$ obtained interprets the semicrystalline structure of $\mathrm{ZnO}$ nanoparticles doped polymer composites. Correspondingly, the occurrence of sharp XRD peaks also authenticates the crystalline nature of ZnO doped PVA composites.

3.4. Mechanical Studies of Pure and Doped PVA Samples. Mechanical properties of the polymer nanocomposites were performed using universal testing machine (UTM). It comprises two metallic grips for griping both ends of the specimen film in order to study the mechanical properties like tensile strength, Young's modulus, and so forth. The lower grip is held fixed, whereas the upper grip is moved up with a constant speed. An electrically driven automatic speed controller, kept above, controls the speed of the upper grip. All mechanical measurements were carried out at room temperature in air. The tensile strength, Young's modulus (modulus of elasticity), and percentage of elongation are used to assess the physical properties of doping of nanoparticles
TABLE 2: The deviation of Urbach energies of PVA doped with different doping concentrations of $\mathrm{ZnO}$ nanoparticles.

\begin{tabular}{lcc}
\hline Sl number & $\begin{array}{c}\text { ZnO doping concentration } \\
(\text { wt\%) }\end{array}$ & $\begin{array}{c}\text { Urbach energy } \\
(\mathrm{eV})\end{array}$ \\
\hline 1 & Pure PVA & 2.47 \\
2 & 1 & 3.22 \\
3 & 5 & 3.78 \\
4 & 7.5 & 4.68 \\
5 & 10 & 5.17 \\
6 & 14 & 6.93 \\
7 & 15 & 7.96 \\
\hline
\end{tabular}

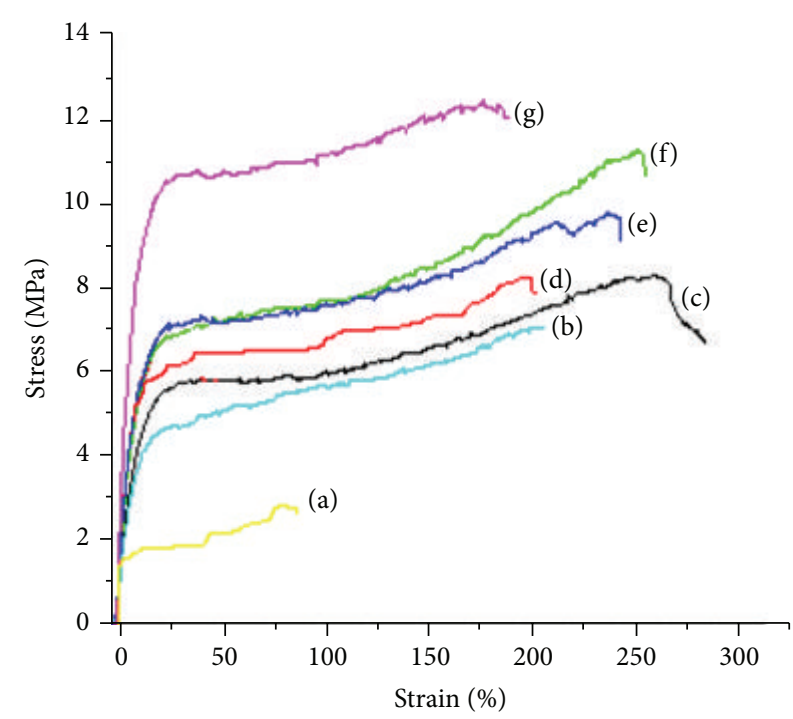

FIGURE 6: Stress-strain curves of PVA/( $x) \mathrm{ZnO}$ with (a) $x=0 \mathrm{wt} \%$, (b) $x=1 \mathrm{wt} \%$, (c) $x=5 \mathrm{wt} \%$, (d) $x=7.5 \mathrm{wt} \%$, (e) $x=10 \mathrm{wt} \%$, (f) $x=14 \mathrm{wt} \%$, and (g) $x=15 \mathrm{wt} \%$.

on polymer matrix through a comparison of experimental results.

The mechanical properties of doped polymer composites generally depend on the intermolecular forces, interaction, and complex formation with the dopant, chain stiffness, and molecular symmetry of the individual polymer [19]. From Table 3 and Figure 6, it is very clear that PVA/ $(x) \mathrm{ZnO}$, where $x=15 \mathrm{wt} \%$, exhibits high tensile strength. The mechanical behavior is also affected by the degree of crystallinity and the surface morphology of the crystalline material. It was found that degree of crystallinity was high for $x=15 \%$ and crystallinity of a polymer increases with the degree of crystallinity increases because of the secondary bonding also. Further, for this reason, the stiffness (elastic modulus) and strength of the polymer nanocomposite also increase. On the other hand, ductility declines as crystallinity increases. Hence, for $x=15 \%$ weight concentration, the maximum stiffness value was found to be $9.8261 \mathrm{kN} / \mathrm{m}$. The maximum percentage elongation at fracture in PVA nanocomposite is observed for $x=7.5 \mathrm{wt} \%$ doping concentration. Thus, a high 
TABLE 3: Mechanical properties of pure and $\mathrm{ZnO}$ nanoparticles doped PVA films.

\begin{tabular}{lccccc}
\hline Sl number & Sample & $\begin{array}{c}\text { Tensile strength } \\
(\mathrm{MPa})\end{array}$ & $\begin{array}{c}\text { Stiffness } \\
(\mathrm{kN} / \mathrm{m})\end{array}$ & $\begin{array}{c}\text { Young's modulus } \\
(\mathrm{MPa})\end{array}$ & $\begin{array}{c}\text { Percentage total } \\
\text { elongation at fracture }\end{array}$ \\
\hline 1 & PVA/0 wt\% ZnO & 2.901 & 5.3490 & 45.330 & 92.53 \\
2 & PVA/1 wt\% ZnO & 6.964 & 5.8880 & 90.585 & 221.50 \\
3 & PVA/5 wt\% ZnO & 7.096 & 6.9059 & 74.658 & 214.55 \\
4 & PVA/7.5 wt\% ZnO & 8.331 & 8.3994 & 86.148 & 295.21 \\
5 & PVA/10 wt\% ZnO & 9.825 & 5.3474 & 82.267 & 251.9 \\
6 & PVA/14 wt\% ZnO & 11.375 & 5.1376 & 70.864 & 263.99 \\
7 & PVA/15 wt\% ZnO & 12.517 & 9.8261 & 196.523 & 195.74 \\
\hline
\end{tabular}

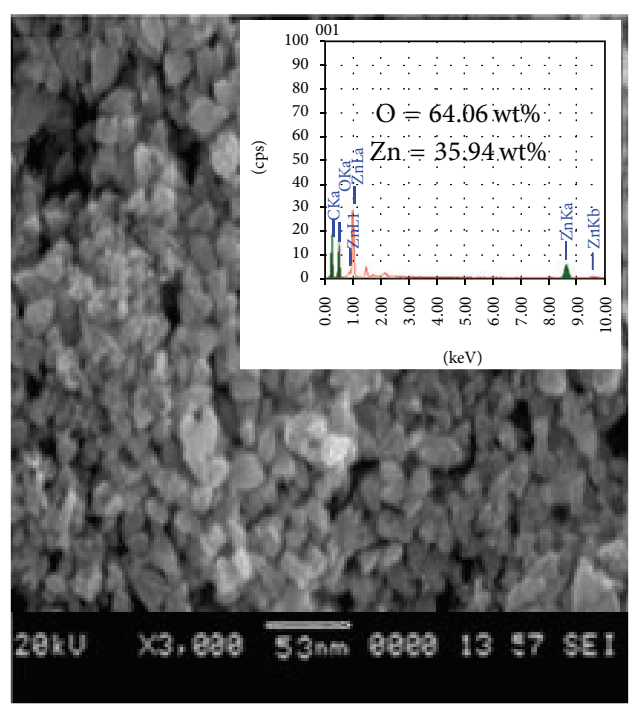

(a)

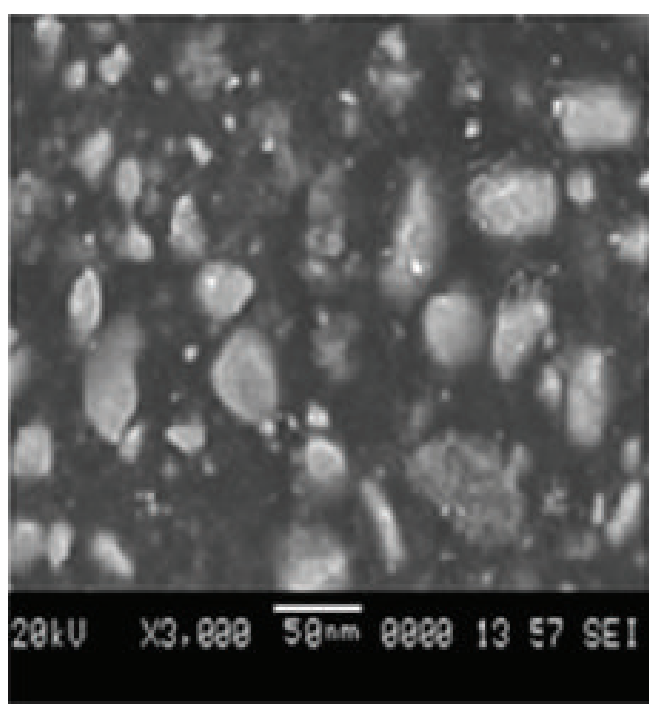

(b)

Figure 7: SEM image of (a) ZnO nanoparticles and (b) PVA doped $\mathrm{ZnO}$ nanoparticles.

ordering of the $\mathrm{ZnO}$ nanodopants in the PVA matrix, shared with intense hydrogen bonding between the nanodopants and congealing of the PVA polymer chains, leads to highly effective load transfer between nanodopants and the polymer. The results indicate that the addition of the $\mathrm{ZnO}$ with weight percentage $x=15 \%$ increases the tensile strength, stiffness, and Young's modulus.

3.5. SEM and EDAX Studies. The scanning electron microscopy (SEM) is used to study the influence of nanoparticles on doping into the polymer matrix through the detection of phase separations and interfaces. Figures 7(a) and 7(b) show the SEM photograph of $\mathrm{ZnO}$ nanoparticles and doped polymer nanocomposite. The observed SEM images of prepared $\mathrm{ZnO}$ nanoparticles structures are found in the form of flakes. The SEM photograph of prepared films explores the homogenous distribution of nanoparticles in the PVA matrix. The investigation of surface morphology of the PVA/ $(x) \mathrm{ZnO}$ polymer composite films shows some aggregates or chunks randomly distributed on the film upper surface. The results specify that some nanosized $\mathrm{ZnO}$ particles would have tended to form small aggregates while dispersing in the PVA polymer matrix. The average particle size of dispersed $\mathrm{ZnO}$ nanoparticles in PVA composite found in the SEM photograph is very near to that of $\mathrm{ZnO}$ particle size calculated from the XRD data.

The chemical composition and homogenous percentage distribution of PVA doped with $\mathrm{ZnO}$ polymer composite film is studied using energy-dispersive analysis of X-rays (EDAX). An EDAX spectrum of synthesized $\mathrm{ZnO}$ nanoparticles taken confirms the presence of $\mathrm{ZnO}$ in the region as shown in Figure 7(a). In order to analyze the EDAX spectra, first the doped polymer nanocomposites films were sputtercovered by gold particles in order to oppose the artifacts produced on the upper surface due to charging (Figure 8). Figure 7(b) and Table 4 explore that the distribution of nanoparticle $\mathrm{ZnO}$ dopants is uniform and confirms the presence of $\mathrm{ZnO}$ in the composite film. 
TABle 4: Percentage distribution of nanosized $\mathrm{ZnO}$ dopants in the composites.

\begin{tabular}{lccccc}
\hline \multicolumn{5}{c}{ ZAF method standardless quantitative analysis } \\
Element & $(\mathrm{keV})$ & Mass\% & Error\% & At\% & K \\
\hline C K & 0.277 & 44.17 & 0.12 & 61.06 & 24.8175 \\
O K & 0.525 & 33.57 & 0.28 & 32.77 & 32.9757 \\
Zn K & 8.630 & 24.26 & 0.89 & 6.16 & 42.2067 \\
Total & & $\mathbf{1 0 0 . 0 0}$ & & $\mathbf{1 0 0 . 0 0}$ & \\
\hline
\end{tabular}

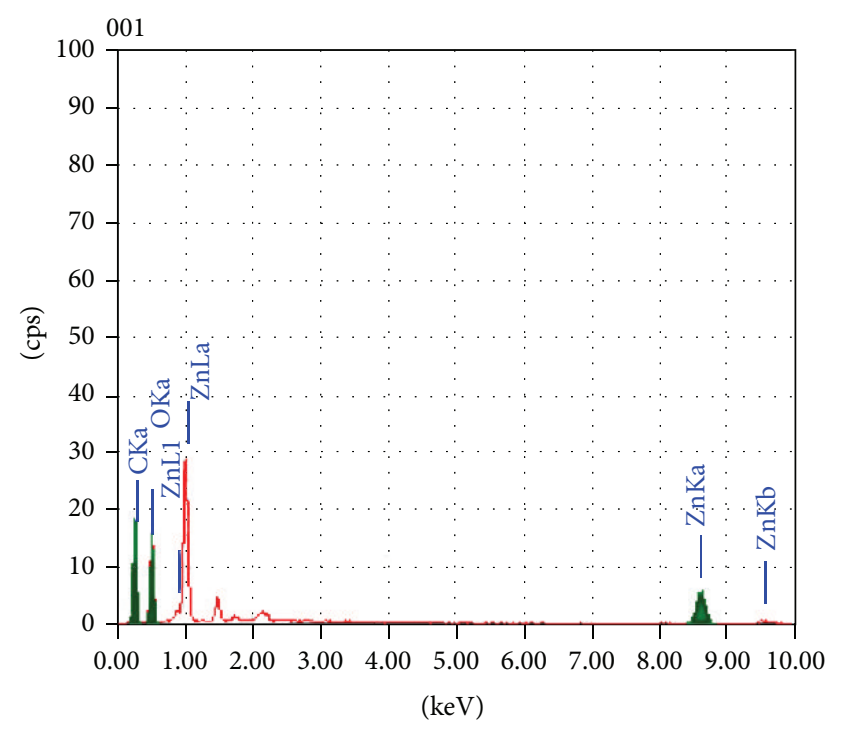

FIgURE 8: EDAX spectra of $\mathrm{ZnO}$ doped PVA nanocomposites.

\section{Conclusions}

The results achieved with the investigated PVA doped with $\mathrm{ZnO}$ polymer nanocomposites prepared by coagulation mixing and solution casting method allow us to draw the following conclusions.

(i) The XRD analysis shows that the synthesized $\mathrm{ZnO}$ nanoparticles have average particle size of $55 \mathrm{~nm}$.

(ii) The interpretation of nanocomposites XRD spectra explores the interaction of dopants by complex formation with the PVA matrix causing the structural variations which changes the crystallinity.

(iii) The FTIR spectrum reveals the interaction occurring between $\mathrm{Zn}$ ions and $\mathrm{OH}$ group of PVA backbone through intra-/intermolecular hydrogen bonding forming a complex.

(iv) The UV-visible spectral studies showed the optical energy gap of $\mathrm{ZnO}$ nanoparticles doped PVA decreases and for $x=15 \%$ the value of $E_{g}=2.756 \mathrm{eV}$.

(v) The value of Urbach energy $\left(E_{\mathrm{u}}\right)$ increases with $\mathrm{ZnO}$ doping concentrations explores the crystalline nature of $\mathrm{ZnO}$ nanoparticles doped polymer composites. (vi) The mechanical studies indicate the microstructural variations and the addition of $\mathrm{ZnO}$ nanostructures for $x=15 \%$ weight doping concentration increase the tensile strength, stiffness, and Young's modulus, whereas, for $x=7.5 \%$ weight doping concentration, the percentage total elongation at fracture increases.

(vii) The scanning electron microscopy images show the $\mathrm{ZnO}$ flake nanoparticles, its homogenous distribution, and the compatibility occurring between the nanoparticles with the PVA matrix.

(viii) The corresponding EDAX spectrum confirms the formation of the composite and explores the elemental compositions of prepared $\mathrm{ZnO}$ nanoparticles doped in basic PVA matrix.

\section{Conflict of Interests}

The authors declare that there is no conflict of interests regarding the publication of this paper.

\section{References}

[1] P. Poizot, S. Laruelle, S. Grugeon, L. Dupont, and J.-M. Tarascon, "Nano-sized transition-metal oxides as negative-electrode materials for lithium-ion batteries," Nature, vol. 407, no. 6803, pp. 496-499, 2000.

[2] M. Ando, K. Kadono, M. Haruta, T. Sakaguchi, and M. Miya, "Large third-order optical nonlinearities in transition-metal oxides," Nature, vol. 374, no. 6523, pp. 625-627, 1995.

[3] R. V. Kumar, Y. Diamant, and A. Gedanken, "Sonochemical synthesis and characterization of nanometer-size transition metal oxides from metal acetates," Chemistry of Materials, vol. 12, no. 8, pp. 2301-2305, 2000.

[4] R. Asahi, T. Morikawa, T. Ohwaki, K. Aoki, and Y. Taga, "Visible-light photocatalysis in nitrogen-doped titanium oxides," Science, vol. 293, no. 5528, pp. 269-271, 2001.

[5] Q. Wan, Q. H. Li, Y. J. Chen et al., "Fabrication and ethanol sensing characteristics of $\mathrm{ZnO}$ nanowire gas sensors," Applied Physics Letters, vol. 84, no. 18, pp. 3654-3656, 2004.

[6] D. C. Reynolds, D. C. Look, B. Jogai et al., "Neutral-donorbound-exciton complexes in ZnO crystals," Physical Review B: Condensed Matter and Materials Physics, vol. 57, no. 19, pp. 12151-12155, 1998.

[7] R. Bouzerara, S. Achour, N. Tabet, and S. Zerkout, "Synthesis and characterisation of $\mathrm{ZnO} / \mathrm{PVA}$ composite nanofibres by electrospinning," International Journal of Nanoparticles, vol. 4, no. 1, pp. 10-19, 2011.

[8] M. Girish Joshi, S. M. Khatake, S. Kaleemulla, N. Madhusudhana Rao, and C. Teresa, "Effect of dopant and DC bias potential on dielectric properties of polyvinyl alcohol (PVA)/ $\mathrm{PbTiO}_{3}$ composite films," Current Applied Physics, vol. 11, no. 6, pp. 13221325, 2011.

[9] D. M. Fernandes, J. L. Andrade, M. K. Lima et al., “Thermal and photochemical effects on the structure, morphology, thermal and optical properties of PVA/ $\mathrm{Ni}_{0.04} \mathrm{Zn}_{0.96} \mathrm{O}$ and PVA/ $\mathrm{Fe}_{0.03} \mathrm{Zn}_{0.97} \mathrm{O}$ nanocomposite films," Polymer Degradation and Stability, vol. 98, no. 9, pp. 1862-1868, 2013.

[10] K. Nejati, Z. Rezvani, and R. Pakizevand, "Synthesis of $\mathrm{ZnO}$ nanoparticles and investigation of the ionic template effect on 
their size and shape," International Nano Letters, vol. 1, no. 2, pp. 75-81, 2011.

[11] H. M. Zidan, "Structural properties of $\mathrm{CrF}_{3}$ - and $\mathrm{MnCl}_{2}$-filled poly(vinyl alcohol) films," Journal of Applied Polymer Science, vol. 88, no. 5, pp. 1115-1120, 2003.

[12] M. S. Selim, R. Seoudi, and A. A. Shabaka, "Polymer based films embedded with high content of ZnSe nanoparticles," Materials Letters, vol. 59, no. 21, pp. 2650-2654, 2005.

[13] E. J. Shin, Y. H. Lee, and S. C. Choi, "Study on the structure and processibility of the iodinated poly(vinyl alcohol). I. Thermal analyses of iodinated poly(vinyl alcohol) films," Journal of Applied Polymer Science, vol. 91, no. 4, pp. 2407-2415, 2004.

[14] M. A. El-Ahdal, "Radiation effect on the molecular structure of dyed poly(vinyl alcohol)," International Journal of Polymeric Materials, vol. 48, no. 1, pp. 17-28, 2000.

[15] K. A. M. Abd El-Kader and S. F. Abdel Hamied, "Preparation of poly(vinyl alcohol) films with promising physical properties in comparison with commercial polyethylene film," Journal of Applied Polymer Science, vol. 86, no. 5, pp. 1219-1226, 2002.

[16] N. F. Mott and E. A. Devis, Electronic Process in Non-Crystalline Materials, Oxford University Press, Oxford, UK, 2nd edition, 1979.

[17] J. Tauc, "Optical properties of solids," in Optical Properties of Solid, F. Abeles, Ed., p. 277, North-Holland, Amsterdam, The Netherlands, 1972.

[18] F. Urbach, "The long-wavelength edge of photographic sensitivity and of the electronic absorption of solids," Physical Review, vol. 92, no. 5, pp. 1324-1325, 1953.

[19] Z. H. Mbhele, M. G. Salemane, C. G. C. E. van Sittert, J. M. Nedeljković, V. Djoković, and A. S. Luyt, "Fabrication and characterization of silver-polyvinyl alcohol nanocomposites," Chemistry of Materials, vol. 15, no. 26, pp. 5019-5024, 2003. 

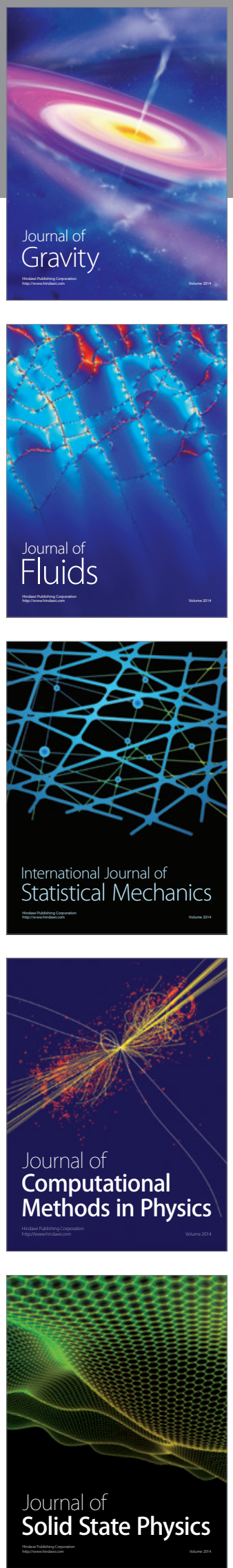

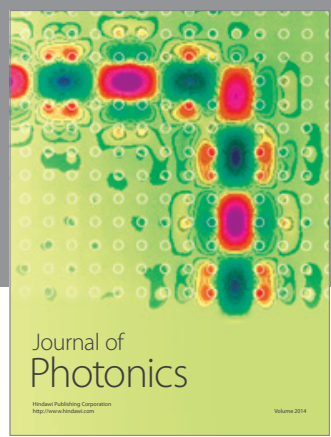

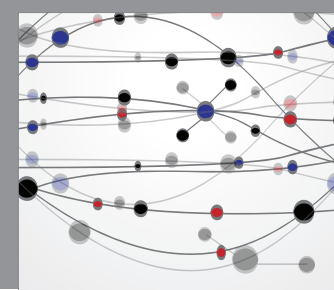

The Scientific World Journal

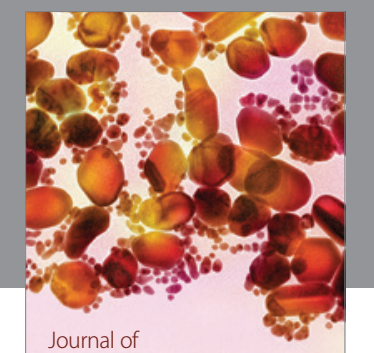

Soft Matter
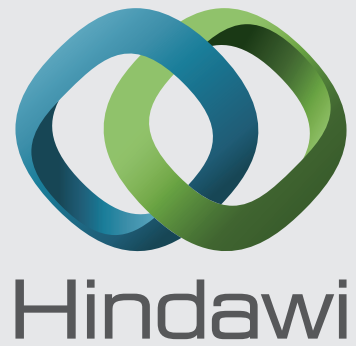

Submit your manuscripts at

http://www.hindawi.com
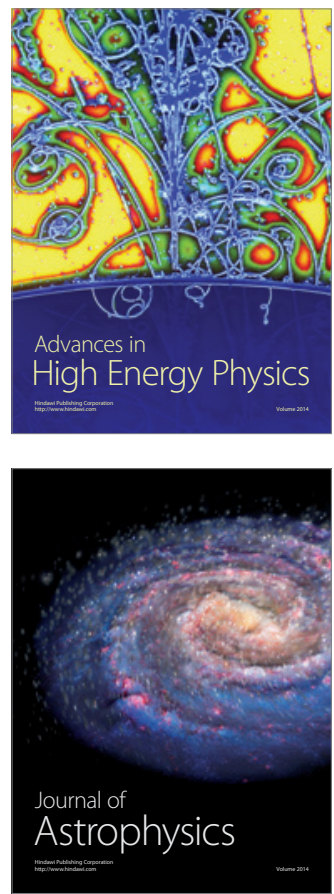
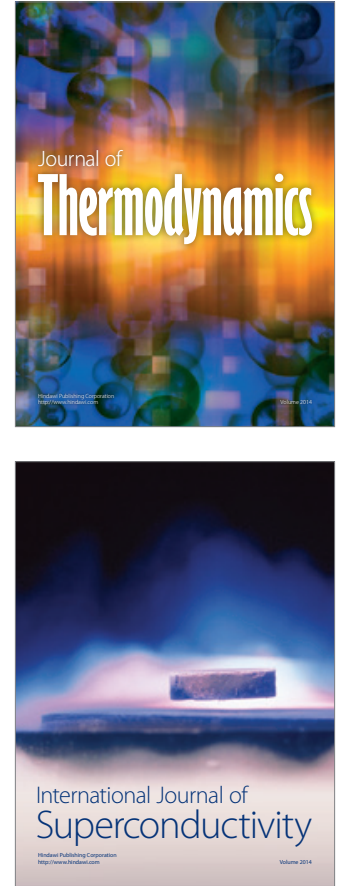
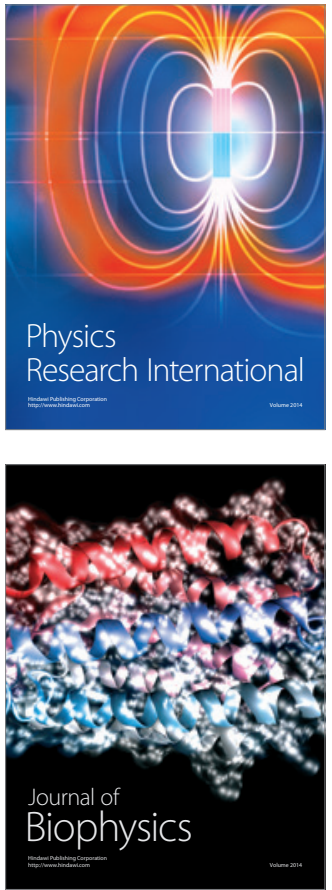
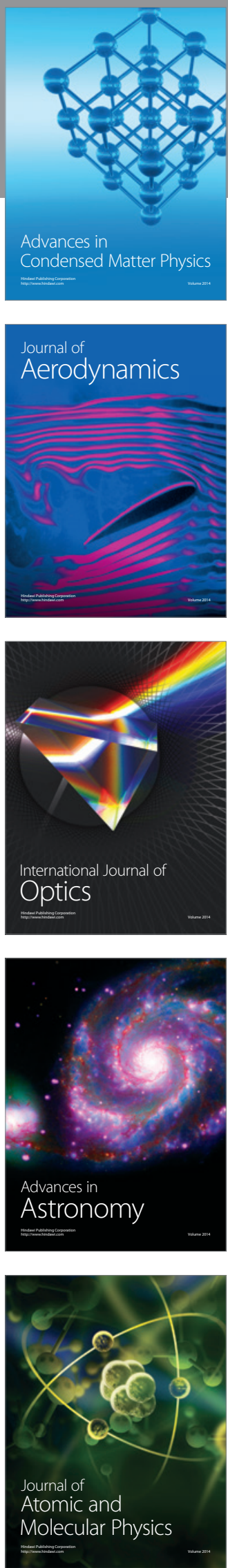